\title{
Will Work-Family Guilt Experiences during the COVID-19 Pandemic Straitjacket Women into Prioritizing their Family?
}

Johanna S. W. Kruger ${ }^{1}$, Belle Derks ${ }^{1}$, Francesca Manzi², Lianne Aarntzen ${ }^{3}$, Ilona Domen ${ }^{1}$, Larisa Riedijk ${ }^{1}$, Dominique Rijshouwer ${ }^{4}$, Ruth van Veelen ${ }^{1}$, Melissa Vink ${ }^{1}$, and Reine van $\operatorname{der} \mathrm{Wal}^{1}$

${ }^{1}$ Department of Social, Health \& Organizational Psychology, Utrecht University

${ }^{2}$ Department of Management, London School of Economics

${ }^{3}$ Department of Educational Science, University of Twente

${ }^{4}$ Department of Research (Academic Affairs), Utrecht University 


\begin{abstract}
The onset of the COVID-19 pandemic drastically changed the circumstances for parents to combine work and care. We examined work-family guilt among working parents in the Netherlands during the first year of the COVID-19-pandemic (2020). In a cross-sectional survey study with two time points (March and December 2020) in a sample of working parents $(N=574)$ in the Netherlands, we revealed three key findings. (1) On average, mothers experienced more guilt towards their family for time and energy invested in work instead of family (work-family guilt) than fathers. (2) Parents with essential occupations (regardless of gender) reported significantly stronger experiences of work-family guilt during the first year of the pandemic compared to parents with non-essential occupations. (3) Parents who experienced stronger work-family guilt were more likely to compensate for their guilt by prioritizing family over work and self (by foregoing their leisure time or intending to reduce workhours in order to be with their family). Together these findings show that in terms of combining work and family, the situation is clearly harder on some more than others, namely mothers and essential workers. These findings demonstrate the gendered experience of workfamily guilt and the asymmetrical impact of the COVID-19 pandemic on the work-family experiences of parents.
\end{abstract}

Keywords: COVID-19, work-family guilt, work and family, gender, parenting, essential occupations 
As a working mother, I would say that the load is unbearable. We are picking ourselves up every hour to meet the needs of everyone around us [...] My seven-yearold daughter complains to me because I can't play with her. The times of work and those of care are totally mixed. (O’Reilly, 2020, p.15)

The experience of guilt when work interferes with family in a negative way (i.e., work-family guilt; Borelli et al., 2017), has been found to be particularly prevalent amongst mothers compared to fathers in heterosexual couples (Borelli et al., 2016, 2017). This is demonstrated in popular culture by the coining of the term 'mom guilt'. During the COVID19 pandemic, the conditions under which parents combined work and family drastically changed. Government measures to curb the effects of the pandemic, including school closures and work-from-home orders, disrupted people's lives and forced many parents to renegotiate work-family arrangements with their partners. According to a study conducted during the Spring 2020 lockdown, although fathers did more compared to before the pandemic, mothers still ended up shouldering a disproportionate amount of the household and care tasks and were more likely to rearrange their work schedules (Yerkes et al., 2020). The above quote demonstrates that mothers may be experiencing this burden not only on a practical level (with less time to work and for leisure), but also on a psychological level, by experiencing higher levels of work-family guilt.

In the current study we examine the experience of work-family guilt amongst working parents during the pandemic and test the gendered work-family guilt hypothesis, which proposes that mothers experience more guilt towards their family for time and energy invested in work instead of family (work-family guilt) than fathers. If mothers experienced higher work family-guilt than fathers, this has important implications for gender equality and women in the workplace, since high levels of work-family guilt are associated with 
compensatory behaviors to reduce the guilt, such as reducing workhours in order to prioritize family. Identifying which groups were the most vulnerable to experience work-family guilt throughout the first year of the pandemic can help guide organizations and policy makers through yet still uncertain times of the pandemic and in a post-pandemic future. In a crosssectional survey study with two time points (March 2020 and December 2020) in a convenience sample of working parents in the Netherlands, this study aims to shed light on working parents' experiences of work-family guilt during the first year of the COVID-19 pandemic.

COVID-19 is a unique moment to study work-family concepts. Since the challenges and changes due to the lockdown measures strongly impacted parents' work-family balance, the pandemic presents social psychological researchers with the rare opportunity to better understand the emotions parents experience when they can no longer rely on the arrangements they have made to combine work and family. Furthermore, this situation offers the chance to determine how the response measures taken to curb COVID-19 have affected parents in their combination of work and care. The present study builds on the modest but growing pool of research on the effects of the COVID-19 pandemic on the interface of work and family (e.g., Giurge et al., 2021; Shockley et al., 2021; Yerkes et al., 2020). To our knowledge at the time of writing there is a lack of literature examining work-family guilt during the pandemic. The current study addresses the critical gap in the COVID-19 workfamily literature.

\section{The Interface of Work and Family during COVID-19}

The onset of the COVID-19 pandemic in March 2020 sweepingly changed everyone's lives. In terms of work-family balance, the response measures to curb the effects of the pandemic during the initial lockdown in March 2020 quickly blurred boundaries between work and private life. School and childcare closures were met with work-from-home orders. 
The strict measures during the lockdown in March 2020 presented parents with a difficult situation. A large part of the burden was lifted when COVID-19 response measures eased including the reopening of schools and childcare. Meanwhile, workers in essential versus non-essential occupations were faced with its different challenges in combining paid work with care. Non-essential workers with children had to work from home, while juggling their child's care or schooling. Essential workers with children had to continue going to work onlocation to keep society running and were supported in their efforts with emergency childcare or schooling for their children.

Amidst the uncertainty, parents were forced to renegotiate household task division arrangements with their partners. Recent findings on the effect of the March 2020 lockdown have showed that highly gendered task division arrangements prevailed with women taking on the lion's share of the tasks (Yerkes et al., 2020) and, at the same time, reporting low wellbeing than men (Giurge et al., 2021). In a survey of diverse samples with over 30,000 respondents across 5 countries, Giurge et al. (2021) found pervasive gender differences in time use during the lockdowns due to the COVID-19 pandemic in 2020. Giurge et al. (2021) showed women, especially mothers, spent more time on household and care tasks than men and reported a significant increase in time spent on tasks compared to pre-pandemic. In turn, to the extent that women spent more time on household tasks than men, time spent completing household tasks was linked to lower well-being. These findings were corroborated by Shockley et al. (2021), who found that the most common task division strategy during COVID-19 amongst dual-earner couples in the United States involved wives working from home and taking on all childcare duties with little adjustment to the husband's work roles. This most common and unequal division of labor experienced the least favorable outcomes of all other arrangements, including lowest job performance, lowest family cohesion, and highest relationship tension (Shockley et al., 2021). In a representative sample 
of Dutch parents, Yerkes et al. (2020), however, notably found that, while mothers did in fact do the lion's share of household and caregiving tasks, the gap did decrease somewhat since fathers reported doing (somewhat) more childcare and households tasks during the lockdown compared to before (an improvement in egalitarian task division that later vanished in their November wave, see Remery et al., 2021).

\section{Gendered Experience of Work-Family Guilt}

Work-family guilt refers to the experience of guilt when work interferes with family in a negative way (Borelli et al., 2016, 2017). Previous research has found that on average women, and in particular mothers, experience more work-family guilt than men, or even fathers (Aycan \& Eskin, 2005; Borelli et al., 2016, 2017; Glavin et al., 2011; Sousa et al., 2018). Borelli et al. (2016) found that mothers conveyed stronger feelings of guilt relating to work interfering with family, and specifically to its impact on their children, than fathers did. These gender differences persisted above and beyond general guilt, further highlighting that mothers' higher work-family guilt is not simply due to women having a higher propensity for guilt (Borelli et al., 2016).

Instead, the gendered experience of work-family guilt, of women experiencing more work-family guilt than men, might be explained by traditional gender stereotypes. Despite changing gender dynamics in society and the increasing number of women working outside of the home (Geiger \& Parker, 2018), gender stereotypes persist and remain resistant to change (Haines et al., 2016). Women still take on disproportionately more domestic tasks than men do (Craig \& Mullan, 2010). Thus, while the roles of being both a worker and a parent are central to many working mothers' and fathers' identities, how these roles are balanced and what it means to fulfil each role varies for mothers and fathers. Social role theory (Eagly \& Wood, 1999, 2016) posits that women are seen as caregivers and fathers are seen as breadwinners. This difference in gender roles results in gender stereotypes: men are 
expected to be agentic (i.e., independent, ambitious) and women are expected to be communal (i.e., warm, concerned about others; Heilman, 2001). These gender stereotypes are not only descriptive, but they are also prescriptive (dictate what women and men should be like) and proscriptive (dictate what women and men should not be like; Heilman, 2001). Therefore, when a woman does not fulfil her role as caregiver or a man does not fulfil his role as breadwinner, they are likely to receive social penalties such as being disliked or disrespected (Eagly \& Karau, 2002; Heilman \& Okimoto, 2007; Heilman \& Wallen, 2010; Rudman et al., 2012).

The Role Prioritization model (Haines \& Stroessner, 2019) further explains that parents' behavior will be judged as acceptable - as long as they prioritize the responsibilities that fit with their gender role. Therefore, a father's prioritization of work is compatible with the responsibilities to the family due to his breadwinner role. A mother's prioritization of work, however, is incompatible with her caregiving role. Due to this friction between work and their caregiver role, mothers experience more guilt resulting from work interfering with family (i.e., work-family guilt) than fathers do. Research has found that the stronger a parent's internalized traditional gender stereotypes, the more work-family guilt mothers experience and the less work-family guilt fathers experience in a scenario of prioritizing work over family (Aarntzen, 2020). As suggested by Aarntzen's (2020) findings, traditional implicit gender stereotypes (mother as caregiver, father as breadwinner) help explain the gendered experience of work-family guilt.

\section{Mixed Findings on Gender Differences in Work-Family Guilt}

While multiple studies have found that on average women experience greater workfamily guilt than men (Aycan \& Eskin, 2005; Borelli et al., 2016, 2017; Glavin et al., 2011; Sousa et al., 2018), other studies, including a large cross-cultural study in which 10 countries were compared (Korabik, 2017), found comparable levels of work-family guilt amongst men 
and women (Gonçalves et al., 2018; Martínez et al., 2011). These mixed findings across different studies suggest that the relationship between gender and work-family guilt still remains unclear.

One important factor may be the large heterogeneity in study design within the gender difference literature on work-family guilt. Many previous studies do not control for workfamily situations that are already gendered (Korabik, 2017; Livingston \& Judge, 2008; Martínez et al., 2011). For instance, a man working a 40-hour week and a woman working a 20-hour week reporting equal levels of guilt is not comparable. What would happen when workhours would be equal? The gender difference in workhours needs to be taken into account when assessing the interface of work and family and yet many studies fail to control for this (Gonçalves et al., 2018; Martínez et al., 2011).

We argue that due to the motivational nature of guilt, parents will combine work and family in such a way to minimize their guilt. Due to the caregiving role of women, mothers will feel more guilty about prioritizing work over family compared to fathers, and as such minimize their workhours or arrange their schedule in order to decrease their guilt. Therefore, a measure of work-family guilt after this arrangement of combining work and family may not indicate gender differences in work-family guilt. However, the onset of the COVID-19 pandemic was a shock to the system and disrupted the equilibrium of parents' work-family arrangements. In these times of change, parents were forced to redesign their combination of work and care duties under strenuous and challenging conditions. As such, the pandemic, and particularly the stricter measures during lockdown, may have made gender differences in work-family guilt more salient by falling back on traditional gender roles and having women adjust their schedules in order 'pick up the slack' at home. Given that women are expected to prioritize caregiving over work (Role Prioritization Model), mothers will likely experience 
more work-family guilt than fathers, for whom it is gender-congruent to prioritize work over family. Based on the above argumentation, we predict that:

Hypothesis 1: Working mothers experienced significantly more work-family guilt compared to working fathers during times of COVID-19.

\section{Controlling for Unique Work-Family Experiences during COVID}

Given the unique situation of the pandemic, a parent's work-family experiences uniquely differed depending one's type of occupation: essential or non-essential. During the COVID-19 pandemic, governments have declared jobs deemed crucial to keeping society running (e.g., healthcare, education, food supply; Government of the Netherlands, 2020) as essential occupations. Essential workers, who were at the frontlines of the pandemic, received practical support from the government for their efforts, such as that their children were still enabled to go to school or daycare when these facilities were closed for children of parents with non-essential jobs. Furthermore, during the March 2020 lockdown, moments of gratitude for essential workers, took place in the Netherlands in the form of community-led applause or other forms of celebration. As such, the role of having one's occupation declared essential (vs. non-essential), and vital to the running of society, may impact the way that working parents experience the interface of work and family; having an essential occupation may make people feel less guilty when prioritizing work over family since they have an important reason to do so and are valued by society when they do. Furthermore, essential workers are overwhelmingly more likely to be women (Yerkes et al., 2020). Therefore, in addition to workhours (which are gendered) and for age of youngest child and number of children (to account for greater caretaking duties), we plan to control for the effect of essential vs. non-essential occupations in the analysis of work-family guilt and will account for it in the examination of gender effects. 


\section{Compensating for Work-Family Guilt}

What happens once parents experience work-family guilt? Not only is work-family guilt associated with various negative consequences, such as increased psychological distress (Glavin et al., 2011) and decreased happiness (Aarntzen et al., 2019), work-family guilt helps dictate parents' work-family choices. In general guilt literature, guilt is defined as a moral emotion that arises when people perceive that they have violated a societal or moral standard (Tangney et al., 2007). The effect of guilt on interpersonal behavior is targeted at remediating relationships that were harmed by the guilt-inducing act (Cryder et al., 2012). Therefore, in moments of prioritizing work over family, mothers, unlike fathers, are more likely to feel like that they have violated the societal standards of what it means to be a good parent and as a result feel more guilty. This guilt has consequences, as it prompts mothers, in turn, to compensate for the guilt by prioritizing their family for example by reducing their workhours or foregoing their leisure time (Aarntzen et al., 2019). Work-family guilt, as Aarntzen et al. (2019) found in a sample of mothers, functions as a motivator to prioritize caretaking tasks over work in order to cope with one's guilt, leading mothers who feel guilty to want to comply more strongly with gender norms after feeling guilty. Reduction of workhours, particularly amongst women, can have significant consequences for their representation in the workforce and gender (in)equality. Furthermore, reduction of leisure time, which is an important indicator of quality of life, is consequential to a person's wellbeing (Somarriba \& Pena, 2009). In the current study, we aim to examine whether work-family guilt positively predicts parents' family prioritization (i.e., reduce workhours or time for oneself in order to spend more time with family) in a sample of both mothers and fathers during the first year of the COVID-19 pandemic (2020). Furthermore, we aim to examine whether work-family guilt mediates the relationship between gender and the degree to which parents prioritize their family. Based on Aarntzen et al. (2019), we predict that: 
Hypothesis 2: Work-family guilt positively predicts family prioritization in parents.

Hypothesis 3: Higher work-family guilt experienced by mothers mediates the effect of gender on family prioritization.

\section{Methods}

\section{Design \& Procedure}

We examined these hypotheses in an empirical study using two cross-sectional samples of working parents in the Netherlands. Data was collected during the first two waves of the Gender in times of COVID-19 study, a survey conducted by all authors spanning questions on five themes (romantic relationships, work and family, professional identification, gender stereotypes, and experienced stress). This study only focuses on questions from the work-family and participant background section. The survey was conducted online using Qualtrics software (Provo, UT, United States) and took 15-20 minutes to complete. Participants first read an informed consent, where they were informed that their responses would be treated confidentially, that participation was voluntary and that participants had to be at least 18 years old, in a romantic relationship and have lived with their partner for longer than 6 months. At the end of the survey, participants read a debriefing in which they were thanked for their participation and were able to provide comments or feedback. With the incentive of a report detailing survey results, participants were finally asked if they were interested in being contacted for future study waves, in which case they could leave their email address (stored separately from their study data). The survey was approved by our university's Ethnics Committee.

Data were collected during the first year of the COVID-19 pandemic. Wave 1 was collected between May 27 - June 5, 2020 but most questions referred to the March 2020 lockdown in the Netherlands. Wave 2 included both follow-up participants and new participants. Wave 2 was collected between December 4 and December 20, 2020 and referred 
to the previous four weeks. During this time the Netherlands was in a partial lockdown until December 14, with eased measures as compared to the March 2020 lockdown (e.g., schools and daycares were open). Four days before the end of data collection on December 15, the Netherlands entered a hard lockdown (with stricter measures than the March lockdown). However, since survey questions referred to the past month, data collection proceeded as planned until December 20, 2020. See Appendix A for an overview of COVID-19 response measures during data collection.

\section{Participants}

Participants were 574 working parents $(65.5 \%$ women) in a heterosexual relationship. This subset of participants was part of a larger sample of participants who were recruited through convenience sampling (through social media and researchers' personal network) in two waves of data collection (Wave 1: May - June 2020; Wave 2: November - December 2020). Wave 1 participants who indicated they wanted to be contacted again for follow-up research were contacted via email for Wave 2 recruitment. At Wave 1, participants had to be over 18 years old, in a romantic relationship and have lived with their partner for longer than 6 months. New participants at Wave 2, also had to meet these criteria. Follow-up participants at Wave 2 were included regardless of their current relationship status. In total, 540 people responded at wave $1^{1}$ and 1100 people responded at wave 2 . Based on inclusion criteria for the current study, we only included a subset of participants who were currently employed,

${ }^{1}$ In order to minimize the length of the survey, the wave 1 questionnaire was split into two versions (A and B) and participants were randomly assigned to a version. Version A included 540 participants and version B included 541 participants. As the data for the current study were collected in version A, only this version will be referred to for Wave 1. 
had at least one child (living at home), self-identified as either woman or $\operatorname{man}^{2}$ and who were in a heterosexual relationship ${ }^{3}$. The final sample of $N=574$ participants included 57 followup participants (77.19\% women), who participated in Wave 1 and 2. Of the participants who only participated in one wave, $N=229(66.38 \%$ women $)$ participated in Wave 1 and $N=288$ (62.5\% women) participated in Wave 2. Please note that the final sample contained missing values on study variables and, as such, sample sizes vary for subsequent analyses due listwise deletion.

The average age of the sample was 42.97 years old $(S D=7.86)$. Participants had one to five children living at home $(M=2.02 ; S D=.84)$. Participants' youngest child was on average 8.16 years old $(S D=7.14)$. The sample consisted of relatively highly educated respondents. Most participants $(88.8 \%$ ) completed a tertiary education (of which $63.2 \%$ completed a Dutch university degree and $25.6 \%$ a higher vocational degree) and $11.1 \%$ completed a higher secondary education or lower. Before COVID-19, participants worked on average 35.1 hours per week $(S D=9.5)$. Men worked on average 8.4 hours more per week than women $\left(M_{m e n}=40.6\right.$ hours; $S D=8.7 ; M_{\text {women }}=32.2$ hours; $\left.S D=8.6\right)$, which is typical of the Dutch situation where $23.3 \%$ of men work fulltime, but $73.4 \%$ percent of women work part-time (36 hour or less; CBS \& SCP, 2020). During COVID-19, 52.1\% of the sample had a non-essential occupation and $38.7 \%$ had an essential occupation (missingness of 9.2\%). For an overview and frequency of the types of essential occupations, see Table 1.

${ }^{2}$ Due to the low number of respondents who indicated a gender other than woman or man $(N=1)$, we chose to only include only self-identified women and men in the sample.

${ }^{3}$ Due to the low number of non-heterosexual respondents $(N=7)$, we chose to only include heterosexual respondents in our analysis. 


\section{Measures}

All study variables were measured in the Gender in times of COVID-19 survey. For most variables only a single or two-item measures were used in order to keep the survey short to facilitate a reasonable response rate. Original measures can be found in Appendix B, which were translated to Dutch in the survey.

\section{Work-family guilt}

Work-family guilt was measured on a 7-point Likert scale using one item based on the Morgan and King's (2012) adaptation of Netemeyer et al.'s scale (1996; i.e., "I feel guilty that because of my work I am not able to take care of my family as well as I would like in this situation" $[1$ = strongly disagree, 7 = strongly agree $]$ ).

\section{Family prioritization}

Participants' family prioritization was measured by their consideration of reducing their workhours ${ }^{4}$ and their reduction of leisure time in order to spend more time with one's family. The measure consisted of two items on a seven-point Likert scale (i.e., 'Over the past few weeks, I have been thinking about how I can reduce my workhours so that I can spend more time with my partner/child(ren)' and 'In the past few weeks, I have spent time that I actually wanted to spend on myself (e.g., for a hobby or to read a fun book), yet spent it on my partner/child(ren)' $[1=$ strongly disagree, $7=$ strongly agree $], r=.460, p<.001)$.

${ }^{4}$ We chose to measure the consideration of reducing workhours instead of whether participants reduced their workhours for two reasons: the lack of control many workers have over reducing their workhours and the lag time it may take to reduce one's workhours. See Appendix $\mathrm{C}$ for further explanation. 


\section{Essential occupations}

Participants were asked whether their employment fell within the government's defined sectors of essential occupations during the COVID-19 crisis (Government of the Netherlands, 2020), which were listed within a multiple-choice question ('Below is a list of occupations classified as "essential occupations" by the Dutch government. Do you currently have an essential occupation according to this list? Click the answer that best fits your work situation). A dummy variable for essential occupations (essential occupation, non-essential occupation) was created from this.

\section{Demographic variables}

Demographic variables included: gender (multiple choice question with man, woman, other; please specify), participant age in years, number of children living at home, ages of children living at home (from which age of youngest child was computed; measured by an open-ended question with a text box for each child), educational level (multiple choice), number of work-hours before the COVID-19 crisis.

\section{Results}

\section{H1: Do mothers experience more work-family guilt than fathers during COVID-19?}

The first hypothesis ('Mothers experienced significantly more work-family guilt than fathers during times of COVID-19') was tested using a hierarchical regression. In order to increase power, the question was analyzed in a collapsed sample of unique Wave 1 and Wave 2 participants (i.e., follow-up participants were only included at Wave 1), resulting in a final sample of $N=506$ (after listwise deletion ). To control for the effect of time of measurement, time was included as a control variable in the analysis. In step 1, the control variables time of measurement (Wave 1 or Wave 2), workhours, number of kids, age of youngest child and essential occupations were entered. In step 2, gender was entered. In step 3, the interaction terms with gender were entered for all control variables. 
Means, standard deviation, and intercorrelations are shown in Table 2. Study variables demonstrated low to moderate intercorrelations. Regression results are shown in Table 3. Results at Step 1 revealed that, with the exception of workhours, all control variables contributed significantly to the regression model. Time was the strongest predictor of workfamily guilt, showing that significantly higher guilt was reported at W1, during the March 2020 lockdown, compared to W2, during the partial lockdown in December 2020. The next strongest predictor was essential occupations, showing that essential workers reported significantly more guilt than non-essential workers. Next, age of youngest child (the younger the child, the more guilt was reported), and finally number of children (the more children, the more guilt was reported) likewise significantly predicted work-family guilt. See Table 3 for further results on all control variables. In total, all controls explained $9.8 \%$ of the variation in work-family guilt, $F(5,500)=10.91, p<.001$. Adding the predictor gender at Step 2 explained an additional $3.2 \%$ of the variation in work-family guilt and this change in $R^{2}$ was significant, $\Delta F(1,499)=18.07, p<.001$. Results of Step 2 revealed that, in line with Hypothesis 1, women reported significantly more work-family guilt than men. Adding the interactions terms for gender and the control variables explained an additional $0.9 \%$ of the variation in work-family guilt and this change in $R^{2}$ was not significant, $\Delta F(5,494)=1.07, p$ $=.376$. There were no interactions between gender and the control variables (number of children, age of youngest child, workhours, time and essential occupations) in predicting work-family guilt (see Table 3 for further results).

\section{H2: Does work-family guilt predict compensation by prioritizing family over work and self during COVID-19?}

The second hypothesis ('Work-family guilt positively predicts family prioritization at the same time point during COVID-19') was investigated using a hierarchical regression. As family prioritization was only measured at Wave 2, this hypothesis was only tested amongst 
Wave 2 respondents, resulting in a final sample of $N=298$ (after listwise deletion). At Step 1, the control variables workhours, number of kids, age of youngest child and essential occupations were entered. At Step 2, gender was entered. At Step 3, work-family guilt (mean centered). At Step 4, the interaction term between mean centered Work-family Guilt $\mathrm{x}$ Gender was entered.

Means, standard deviation, and intercorrelations are shown in Table 4. Study variables demonstrated low to moderate associations, with the exception of a strong correlation between predictor work-family guilt and outcome variable family prioritization. Step 1 revealed all control variables contributed significantly to the regression model with the exception of number of kids. Age of youngest child was the strongest predictor of family prioritization (the younger the child, the more family prioritization was reported), followed by essential occupations (essential workers reporting more family prioritization than nonessential workers), and finally workhours (the more hours a parent worked, the more family prioritization they reported). See Table 5 for further results on all control variables. In total, all controls explained $9.5 \%$ of the variation in family prioritization, $F(4,293)=7.70, p<$ .001 . Adding the predictor gender at Step 2 explained an additional $0.7 \%$ of the variation in family prioritization and this change in $R^{2}$ was not significant, $\Delta F(1,292)=2.15, p=.143$. Gender did not significantly predict family prioritization, meaning men and women did not significantly differ in family prioritization. Adding work-family guilt at Step 3 explained an additional $28.7 \%$ of the variation in family prioritization and this change in $R^{2}$ was significant, $\Delta F(1,291)=136.71, p<.001$. In line with the second hypothesis, work-family guilt significantly predicted family prioritization and explained a substantial amount of the total variance of family prioritization. The more work-family guilt a parent reported, the more family prioritization they reported. Finally, adding the interaction term Work-family Guilt x Gender at Step 4 explained no additional detectable variance in family prioritization and was 
not significant, $\Delta F(1,290)=0.08, p=.782$. There was no interaction between work-family guilt and gender in predicting family prioritization (see Table 5 for further results).

\section{H3: Does work-family guilt mediate the relationship between gender and family prioritization?}

The third hypothesis ('Work-family guilt mediates the effect of gender on family prioritization') was investigated using bootstrapping (5000 samples) and model 4 of the PROCESS macro version 3.5.3 (Hayes, 2022). As family prioritization was only measured at Wave 2, this hypothesis was only tested in the sample of Wave 2 respondents resulting in a final sample of $N=298$ (after listwise deletion). Since essential occupations was found to be a significant predictor of work-family guilt and family prioritization and given the theoretical relevance of considering the predictor of essential occupations during COVID-19 given the different work-family situations of essential and non-essential workers, we conducted an additional exploratory analysis of whether work-family guilt mediated the effect of essential occupations on family prioritization. Therefore, two mediation models (see Figure 1 and 2) were tested, with the predictor of gender while controlling for essential occupation and another with the predictor of essential occupation while controlling for gender. The additional control variables workhours, number of kids, and age of youngest child were included in both models.

The mediation analysis with the predictor of gender (while controlling for essential occupation as well as number of kids, workhours, and age of youngest child) of family prioritization indicated that gender was a significant predictor of work-family guilt, $b=.68$, $S E=.24, p=.005$ and that work-family guilt was a significant predictor of family prioritization, $b=.52, S E=.04, p<.001$. Gender was no longer a significant predictor after controlling for the mediator, work-family guilt, $b=-.03, S E=.18, p=.870$, consistent with full mediation. Approximately $39 \%$ of the variance in family prioritization was accounted for 
by the predictors $\left(R^{2}=.39\right)$. Results indicated the indirect coefficient was significant, $b=.35$, $S E=.12,95 \%$ CI $[.13, .60]$. As such, confirming Hypothesis 3, women in our sample reported higher family prioritization because they experienced more work-family guilt.

The mediation analysis for the predictor of essential occupation (while controlling for gender as well as number of kids, workhours, and age of youngest child) on family prioritization indicated that essential occupation was a significant predictor of work-family guilt, $b=.57, S E=.21, p=.008$, and that work-family guilt was a significant predictor of family prioritization, $b=.52, \mathrm{SE}=.04, p<.001$. Essential occupation was no longer a significant predictor after controlling for the mediator, work-family guilt, $b=.10, S E=.16, p$ $=.540$, consistent with full mediation. Approximately $39 \%$ of the variance in family prioritization was accounted for by the predictors $\left(R^{2}=.39\right)$. Results indicated that the indirect coefficient was significant, $b=.29, S E=.11,95 \% \mathrm{CI}[.05, .30]$. This suggests that being an essential worker was associated with stronger family prioritization because essential workers experienced stronger work-family guilt.

\section{Discussion}

In the present study we examined work-family guilt among working parents in the Netherlands during the first year of the COVID-19-pandemic in two surveys (March 2020 and December 2020). There were three main findings. First, we found that, on average, mothers reported to experience more guilt than fathers towards their family for time and energy invested in work instead of family. Second, we found that parents with essential occupations (mothers and fathers) reported significantly stronger experiences of work-family guilt during the first year of the pandemic compared to parents with non-essential occupations. Third, we found that parents who experienced stronger work-family guilt also reported higher family prioritization in that they reported to forego their leisure time in order to be with their family and reported a higher intention to reduce their workhours. The 
unprecedented situation of the COVID-19 pandemic has brought about sweeping changes to everyone's life, and research such as the current study is imperative to better understand and predict the implications of these changes for gender equality. In the following paragraphs, we will discuss our findings, their implications, strengths, and limitations, and present recommendations for policy to mitigate effects of the pandemic on gender equality.

\section{Mothers experience more work-family guilt}

Support was found for our first hypothesis that, even when controlling for their workhours, mothers experienced more work-family guilt than fathers during the first year of the COVID-19 pandemic. This finding is in line with previous research showing that women, and in particular mothers, tend to experience more work-family guilt than men (Aycan \& Eskin, 2005; Borelli et al., 2016, 2017; Glavin et al., 2011; Sousa et al., 2018). We think these results are important because they add to other research carried out at the same time showing that when the equilibrium of parents' work-family arrangements was disrupted due to the pandemic it was women who were most likely to adjust their schedule to the changing circumstances and 'pick up the slack' (Yerkes et al., 2020). Our results show that women did not only do more at home during the lockdowns, they also experienced stronger psychological repercussions of the crisis in that they experienced more work-family guilt while they doing so.

To place these findings further within the context of the pandemic, other recent findings show the disproportionate burden women, especially mothers, experience during COVID-19 in terms of time spent on childcare and household tasks (Giurge et al., 2021; Shockley et al., 2021; Yerkes et al., 2020), and in turn, reporting lower wellbeing (Giurge et al., 2021). As speculated by Giurge et al. (2021), it is possible that the decrease in wellbeing among women resulting from the additional provision of household tasks is driven by the goal conflict of not being able to simultaneously be an ideal employee and a good parent. Our 
finding of high work-family guilt among working mothers fits with this explanation and pinpoints the psychological mechanisms underpinning why this gendered division of labor during COVID-19 undermines mothers' wellbeing.

\section{Essential workers experience more work-family guilt}

We also found that parents with essential occupations reported significantly higher workfamily guilt compared to parents with non-essential occupations. While initially included as a covariate in the regression analysis of work-family guilt, in light of the pandemic and its aftermath, these findings are highly relevant, since they suggest that essential workers are not getting the support that they need at a time when they should be supported the most. The findings that essential workers experience stronger work-family guilt than non-essential workers, is complemented by the recent findings that parents working in an essential occupation experienced the highest levels of work pressure during the lockdown (Yerkes et al., 2020). As noted by Yerkes and colleagues (2020) this is associated with greater healthrelated risks including burnout. The negative outcomes associated with work-family guilt, including increased psychological distress (Glavin et al., 2011) and decreased happiness (Aarntzen et al., 2019), paired together with the fact that essential workers face a greater risk of exposure to the COVID-19 virus due to working on-site (Mutambudzi et al., 2020), is concerning. This begs the question: while front-line workers risk their health and safety to keep our society running during the pandemic, are they receiving all the support we can give them to combine work and family?

\section{Coping with work-family guilt by prioritizing family over work and self}

We found that higher work-family guilt predicted stronger family prioritization among working parents (measured by the intention to reduce workhours and reduction of leisure time in order to spend more time with one's family; H2). Moreover, we found that work-family guilt mediated the relationship between gender and family prioritization $(\mathrm{H} 3)$ as 
well as the relationship between essential occupations and family prioritization (exploratory analysis). This suggests that particularly mothers and parents with essential occupations felt a stronger need to prioritize their family over their leisure time and in terms of future workhours, because they felt guilty about prioritizing their work over their family during the pandemic. The finding of work-family guilt motivating parents to compensate by prioritizing family over work and self as a way of coping is in line with previous findings that workfamily guilt (Aarntzen et al., 2019) and guilt in general (Cryder et al., 2012) prompt individuals to adapt their behavior to remedy the guilt-inducing act. In a diary study of mothers, entailing daily questionnaires for eight consecutive days, Aarntzen et al. (2019) found that work-family guilt was associated with mothers thinking about reducing their workhours, reducing time for themselves, and planning to reserve more time and energy for their children in the future. Building on this, our study, which found that work-family guilt positively predicted parents' actual using leisure time and intentions to reduce workhours in order to spend more time with their family, corroborates Aarntzen et al.'s (2019) findings in a sample of both mothers and fathers. Our findings further suggest that this positive relationship of work-family guilt predicting parents' coping response though compensation does not differ between mothers and fathers. However, since mothers and essential workers experienced greater levels of work-family guilt, they were more likely than fathers and nonessential workers to compensate by prioritizing family over work and me-time. Finding that higher work-family guilt predicts stronger compensation demonstrates the motivational nature of the moral emotion of guilt (Ketelaar \& Tung Au, 2003).

\section{Implications}

The current findings have notable theoretical implications. A lot is known about social roles and how they push women and men towards different choices (Eagly \& Wood, 1999, 2016; Haines \& Stroessner, 2019). The current study shows this theory in action - 
something changes (the onset of the COVID-19 pandemic), and parents are forced to make choices and renegotiate their task division arrangement. By examining the effect of this change on the psychological experiences of parents, while they are coping with these changing demands on their work-family life, we are able to show that current gender roles make it easier for men to combine work and family than for women. Current findings have also substantially contributed to the work-family guilt literature. Research has been inconclusive in its findings regarding gender differences in work-family guilt, with some studies finding gender differences (Aycan \& Eskin, 2005; Borelli et al., 2016, 2017; Glavin et al., 2011; Sousa et al., 2018), while others did not (Gonçalves et al., 2018; Korabik, 2017; Martínez et al., 2011). However, our findings reveal a significant gender difference in workfamily guilt during times of crisis when parents need to renegotiate their task division. It seems likely that gender differences in work family guilt are less likely to arise during stable times when parents have been able to adjust their workhours to the level of work-family guilt they can handle. In such situations, especially in traditional countries like the Netherlands where most women work part-time, men and women report similar levels of guilt, but women work significantly less hours than men do. It is therefore likely that gender differences in work-family guilt are only found in situations that are different from the status quo, such as days on which parents work overtime, in vignette experiments in which parents imagine to work more than they currently do (Aarntzen et al., 2019), or during times of crisis like this current pandemic.

Furthermore, the current study uniquely contributes to the work-family guilt literature in its findings on parents with essential occupations. We found that essential workers experienced significantly more guilt than non-essential workers and that having an essential occupation did not interact with gender on its relationship with work-family guilt. This suggests that the type of occupation matters when examining work-family experiences such 
as work-family guilt. We encourage future research to further examine the role of essential occupations or type of occupations in the experience of work-family guilt.

Our findings also have important practical implications. The current study demonstrated that the impact of the COVID-19 pandemic on the work-family experiences and potential choices of parents in the Netherlands. We showed that in terms of combining work and family during the 2020 pandemic, the situation is significantly more difficult for some more so than others, namely mothers and essential workers. These results are concerning for two reasons.

Firstly, if work-family guilt during the pandemic leads women to more strongly reduce their investment in paid work than men, even if it is on a psychological rather than a practical level (reduced investment rather than actual reduction of workhours) years of improvement in gender equality may be undone. In a survey study of highly qualified women, Hewlett and Luce (2005) showed that nearly four in ten women reported voluntarily taking time off from work, with the majority of women citing family reasons as the most important reason for leaving. The Dutch labor market, in particular, is characterized by the so called 'one-and-a-half earner model' - i.e., women work on average 28.5 hours per week while men work around 39 hours. This gender gap in workhours is the reason that only $64 \%$ of women are currently financially independent (compared to $81 \%$ of men; CBS \& SCP, 2020). In the past years, initiatives have been taken to allow partners to divide paid and unpaid work more equally, resulting in slow but steady increases in women's work hours and men's contribution to childcare. Paired with women's lacking representation in positions of power (Lückerath-Rovers, 2021), it is vital to retain working mothers in the workforce to close the gender gap. However, if in the past years women have experienced more guilt than men about the amount and quality of time they were able to spend with their family, and if this would lead women (but less so men) to conclude that the only way to compensate is to 
give less priority to paid work, these improvements in gender equality may be derailed. It is important to monitor the effects of women's work-family experiences during the pandemic on their work-family choices in the upcoming years.

Secondly, many essential workers in the healthcare and educational sector are women who work in part-time jobs. Graven and Krishnan (2018) reported that in the Netherlands the essential sectors of healthcare and education are characterized by a high proportion of parttime working women. With already existing shortages in these sectors pre-pandemic $(28,400$ vacancies in the final quarter of 2017 in healthcare and 5,300 vacancies in education), it was proposed that the shortages in both these sectors could be solved if women in part-time jobs worked less than one additional hour per week on average (Graven \& Krishnan, 2018). Thus, in turn, if women in these essential sectors were to reduce their workhours by less than one hour per week in order to compensate for their guilt, the expected shortages in these essential work sectors would be exacerbated. Based on the work-family experiences of parents with essential jobs that we show in our study, it is very likely that many parents in essential jobs, especially women, will reduce rather than increase their work hours, which will have detrimental effects for our country's future ability to continue to provide essential services such as healthcare and education.

In terms of policy implications, the current results suggest that the gendered experience of work-family guilt calls for policies that support mothers in their combination of work and family. The gender roles that prescribe family tasks as the priority of women, which are still operant in our society, make us vulnerable to external shocks to our system like the COVID-19 pandemic. One important way for organizations and policy makers to reduce the impact of work-family guilt on mothers and, in turn, prevent their reduction of work hours post-pandemic is by supporting fathers' parental role (e.g., extra paternity leave and stimulating men to take this leave), making fathers and mothers equally responsible for 
childcare. Findings by Aarntzen et al. (2020) suggest that egalitarian organizational norms that support parental roles for both mothers and fathers, resulting in higher uptake of care leave for male employees, predict lower work-family guilt in mothers who work in that organization. Additionally, in order to further support and retain working mothers during COVID-19, organizations should take care that they are not only rewarding employees who maintained high workhours or work output during the pandemic, but instead also work to show their recognition of employees who had to combine work with family during the pandemic. If organizations continue with promoting the 'ideal worker norm' as the only indication of employees' motivation and competence, they stand to lose that part of their talented workforce who simply had to deal with more struggles at home (Williams, 2020). As such, organizations need to redesign their promotion and performance review policies and not simply favor employees who were able to maintain high workhours or output in this time.

Moreover, our findings demonstrate the need for more supportive policies of essential workers. This suggests that the practical support made available to them by the government (e.g., being allowed to still bring their children into school or daycare during lockdowns), was not sufficient. The COVID-19 pandemic, which increased workloads and other stressors among essential workers, merely highlighted already existing vulnerabilities within essential occupations. For instance, pre-pandemic findings demonstrate that high perceived workload among nurses was associated with increased intention to leave the occupation and was mediated by nurses' satisfaction with work-life balance (Holland et al., 2019). Clear steps need to be taken to improve the working conditions of essential workers not only during COVID-19 but also after the pandemic by, e.g., increasing wages and making jobs less mentally demanding, which in turn may reduce work-family guilt. 


\section{Limitations and recommendations for future research}

Our study had several strengths. Firstly, the current study is the first to examine work-family guilt during the time of COVID-19, shedding light on the processes that the first year of the COVID-19 pandemic has triggered in working parents. Secondly, allowing for gender comparisons, the current study examined how parents compensate for work-family guilt by prioritizing family (e.g., reducing workhours or leisure time) in a sample of both mothers and fathers, expanding on Aarntzen et al.'s (2019) findings on mothers.

Next to these strengths, our results must be interpreted in light of a few limitations, which warrant further research. Firstly, an important limitation is the lack of pre-pandemic measures for comparison. However, the December 2020 measure, in which restrictions were much looser than during the lockdown of March 2020 offers a helpful proxy to infer what the effect of stricter measures might entail for parents. While pre-pandemic experience could be addressed in future data collection through retrospective survey measures, given the large span of time this would be asking participants to time back to, a post-pandemic measure might be most fitting and can also offer helpful insights.

Secondly, a single-item measure was used for work-family guilt. This was used in order to keep the survey as short as possible and increase response rates for recurring participants, since shortening surveys helps boost overall response rates (Rogelberg \& Stanton, 2007). While single-item measures for work-family guilt are not uncommon in previous research (Aarntzen et al., 2019; Glavin et al., 2011), they are more vulnerable to bias in interpretation or random measurement error (Aarntzen et al., 2019). Future research with more flexibility regarding survey length, due to for instance a non-longitudinal study design, should consider using the complete eight-item measure by Morgan and King (2012) ${ }^{5}$, upon

5 adapted from Netemeyer et al.'s (1996) work-family conflict scale by adding the stem "I feel guilty when..." 
which the current study's measure is based on, or the seven-item Work-Family Guilt Scale (WFGS; McElwain, 2008).

Thirdly, the current study only measured the intention to reduce workhours and not subsequent behavior, therefore there is no way to know whether participants actually put their intentions to compensate for work-family guilt by reducing their workhours into action. While findings by Yerkes et al. (2020), that mothers were more likely than fathers to rearrange their workhours already provide insight into whether the actual reduction of workhours might be gendered, future research can include a time-lagged within-person measure of compensatory family prioritization behaviors after measuring work-family guilt and compensatory family prioritization intentions in order to determine whether these behaviors were subsequently performed. This can also investigate the causality of the relationship, using temporal precedence as a proxy for causality (Hamaker et al., 2015).

Fourthly, while the sample size for the current study was sizable, the sample was highly educated, cis-gender, and only in heterosexual relationships and therefore not representative of the general population. For future research, findings should be investigated in a representative sample to allow for generalization. Additionally, since past research has investigated work-family guilt only within heterosexual families, an important next step to further our understanding of the work-family guilt in all individuals is to investigate workfamily within non-traditional participants and families as well (including but not limited to same-sex couples, non-binary individuals, single parents).

\section{Conclusion}

This current study demonstrated that the changes in our lives due to the COVID-19 pandemic have affected working parents in significant ways. During stricter COVID-19 measures, parents experienced higher work-family guilt. Building on Yerkes et al.'s (2020) findings, we found that mothers and essential workers appear to be bearing the brunt of the 
pandemic's burden, not only practically (in terms of tasks) but also psychologically (in terms of feeling guilty about working too much). Higher work-family guilt is reported by mothers compared to fathers and by essential workers compared to non-essential workers. Finally, findings demonstrate that work-family guilt triggers parents to compensate for guilt by prioritizing family (i.e., reducing work hours or leisure time) and therefore, as shown by mediation analyses, makes mothers and essential workers more likely to compensate by reducing their work hours or leisure time. Current findings underline the need to optimize policies to provide better work-family support where it is needed most. This will not only help alleviate work-family guilt and its associated negative outcomes (Aarntzen et al., 2019; Glavin et al., 2011) but will also be critical to retain an important part of the workforce in the years to come. We are now nearly two years into the pandemic and will likely not return to 'normal', as we know it, for some time. The current results improve our position to streamline policy measures to support those shouldering the lion's share of the pandemic's burden. 


\section{References}

Aarntzen, L. (2020). Work-family guilt A straightjacket keeping parents in traditional gender roles (Doctoral dissertation, Utrecht University).

Aarntzen, L., Derks, B., van Steenbergen, E., Ryan, M., \& van der Lippe, T. (2019). Workfamily guilt as a straightjacket. An interview and diary study on consequences of mothers' work-family guilt. Journal of Vocational Behavior, 115, 103336. https://doi.org/10.1016/j.jvb.2019.103336

Aycan, Z., \& Eskin, M. (2005). Relative Contributions of Childcare, Spousal Support, and Organizational Support in Reducing Work-Family Conflict for Men and Women: The Case of Turkey 1. Sex Roles, 53. https://doi.org/10.1007/s11199-005-7134-8

Borelli, J. L., Nelson, S. K., River, L. M., Birken, S. A., \& Moss-Racusin, C. (2016). Gender Differences in Work-Family Guilt in Parents of Young Children. Sex Roles, 76(5-6), 356-368. https://doi.org/10.1007/s11199-016-0579-0

Borelli, J. L., Nelson-Coffey, S. K., River, L. M., Birken, S. A., \& Moss-Racusin, C. (2017). Bringing Work Home: Gender and Parenting Correlates of Work-Family Guilt among Parents of Toddlers. Journal of Child and Family Studies, 26(6), 1734-1745. https://doi.org/10.1007/s10826-017-0693-9

Centraal Bureau voor de Statistiek (CBS), \& Sociaal en Cultureel Planbureau (SCP). (2020). Emancipatiemonitor 2020. https://futurecommunication.nl

Craig, L., \& Mullan, K. (2010). Parenthood, gender and work-family time in the United States, Australia, Italy, France, and Denmark. Journal of Marriage and Family, 72(5), 1344-1361. https://doi.org/10.1111/j.1741-3737.2010.00769.x

Cryder, C. E., Springer, S., \& Morewedge, C. K. (2012). Guilty feelings, targeted actions. Personality and Social Psychology Bulletin, 38(5), 607-618. https://doi.org/10.1177/0146167211435796 
Eagly, A. H., \& Karau, S. J. (2002). Role congruity theory of prejudice toward female leaders. Psychological Review, 109(3), 573-598. https://doi.org/10.1037/0033295X.109.3.573

Eagly, A. H., \& Wood, W. (1999). The origins of sex differences in human behavior: Evolved dispositions versus social roles. American Psychologist, 54(6), 408-423. https://doi.org/10.1037/0003-066X.54.6.408

Eagly, A. H., \& Wood, W. (2016). Social Role Theory of Sex Differences. In The Wiley Blackwell Encyclopedia of Gender and Sexuality Studies (pp. 1-3). John Wiley \& Sons, Ltd. https://doi.org/10.1002/9781118663219.wbegss183

Geiger, A. W., \& Parker, K. (2018). A look at gender gains and gaps in the U.S. | Pew Research Center. Pew Research Center. http://pewrsr.ch/2HDZtxX

Giurge, L. M., Whillans, A. v., \& Yemiscigil, A. (2021). A multicountry perspective on gender differences in time use during COVID-19. Proceedings of the National Academy of Sciences, 118(12), e2018494118. https://doi.org/10.1073/pnas.2018494118

Glavin, P., Schieman, S., \& Reid, S. (2011). Boundary-spanning work demands and their consequences for guilt and psychological distress. Journal of Health and Social Behavior, 52(1), 43-57. https://doi.org/10.1177/0022146510395023

Gonçalves, G., Sousa, C., Santos, J., Silva, T., \& Korabik, K. (2018). Portuguese Mothers and Fathers Share Similar Levels of Work-Family Guilt According to a Newly Validated Measure. Sex Roles, 78(3-4), 194-207. https://doi.org/10.1007/s11199-017-0782-7

Government of the Netherlands. (2020). COVID-19: childcare for children of people working in crucial sectors.

https://www.government.nl/documents/publications/2020/12/15/childcare-for-childrenof-people-working-in-crucial-sectors 
Graven, W., \& Krishnan, M. (2018). Capturing The Potential: Advancing Gender Equality In The Dutch Labor Market. https://www.mckinsey.com/featured-insights/europe/thepower-of-parity-advancing-gender-equality-in-the-dutch-labor-market

Haines, E. L., Deaux, K., \& Lofaro, N. (2016). The Times They Are a-Changing ... or Are They Not? A Comparison of Gender Stereotypes, 1983-2014. Psychology of Women Quarterly, 40(3), 353-363. https://doi.org/10.1177/0361684316634081

Haines, E. L., \& Stroessner, S. J. (2019). The role prioritization model: How communal men and agentic women can (sometimes) have it all. Social and Personality Psychology Compass, 13(12), e12504. https://doi.org/10.1111/spc3.12504

Hamaker, E., Kuiper, R. M., \& Grasman, R. (2015). A Critique of the Cross-Lagged Panel Model ADAPT (Assessing the Dynamics Between Parenting and Adaptation in Teens; NWO VIDI) View project Multiple indicator RI-CLPM View project. Psychological Methods, 20, 102-116. https://doi.org/10.1037/a0038889

Hayes, A. F. (2022). Introduction to mediation, moderation, and conditional process analysis : a regression-based approach (Third edition). The Guilford Press.

Heilman, M. E. (2001). Description and prescription: How gender stereotypes prevent women's ascent up the organizational ladder. Journal of Social Issues, 57(4), 657-674. https://doi.org/10.1111/0022-4537.00234

Heilman, M. E., \& Okimoto, T. G. (2007). Why are women penalized for success at male tasks?: The implied communality deficit. Journal of Applied Psychology, 92(1), 81-92. https://doi.org/10.1037/0021-9010.92.1.81

Heilman, M. E., \& Wallen, A. S. (2010). Wimpy and undeserving of respect: Penalties for men's gender-inconsistent success. Journal of Experimental Social Psychology, 46(4), 664-667. https://doi.org/10.1016/J.JESP.2010.01.008 
Hewlett, S. A., \& Luce, C. B. (2005). Off-Ramps and On-Ramps: Keeping Talented Women on the Road to Success. Harvard Business Review, 83(3). https://hbr.org/2005/03/offramps-and-on-ramps-keeping-talented-women-on-the-road-to-success

Holland, P., Tham, T. L., Sheehan, C., \& Cooper, B. (2019). The impact of perceived workload on nurse satisfaction with work-life balance and intention to leave the occupation. Applied Nursing Research : ANR, 49, 70-76. https://doi.org/10.1016/J.APNR.2019.06.001

Ketelaar, T., \& Tung Au, W. (2003). The effects of feelings of guilt on the behaviour of uncooperative individuals in repeated social bargaining games: An effect-as-information interpretation of the role of emotion in social interaction. In Cognition and Emotion (Vol. 17, Issue 3, pp. 429-453). Taylor \& Francis Group . https://doi.org/10.1080/02699930143000662

Korabik, K. (2017). The Role of Work-Family Guilt in the Work-Family Interface. In K. Korabik, Z. Aycan, \& R. Ayman (Eds.), The Work-Family Interface in Global Context (pp. 368-391). Routledge. https://doi.org/10.4324/9781315732084-20

Livingston, B. A., \& Judge, T. A. (2008). Emotional Responses to Work-Family Conflict: An Examination of Gender Role Orientation Among Working Men and Women. Journal of Applied Psychology, 93(1), 207-216. https://doi.org/10.1037/0021-9010.93.1.207

Lückerath-Rovers, M. (2021). The Dutch Female Board Index 2021.

Martínez, P., Carrasco, M. J., Aza, G., Blanco, A., \& Espinar, I. (2011). Family Gender Role and Guilt in Spanish Dual-Earner Families. Sex Roles, 65(11-12), 813-826. https://doi.org/10.1007/s11199-011-0031-4

McElwain, A. K. (2008). An examination of the reliability and validity of the Work-Family Guilt Scale. http://atrium.lib.uoguelph.ca/xmlui/handle/10214/20933 
Morgan, W. B., \& King, E. B. (2012). The Association between Work-Family Guilt and Proand Anti-Social Work Behavior. Journal of Social Issues, 68(4), 684-703. https://doi.org/10.1111/j.1540-4560.2012.01771.x

Mutambudzi, M., Niedwiedz, C., MacDonald, E. B., Leyland, A., Mair, F., Anderson, J., Celis-Morales, C., Cleland, J., Forbes, J., Gill, J., Hastie, C., Ho, F., Jani, B., MacKay, D. F., Nicholl, B., O’Donnell, C., Sattar, N., Welsh, P., Pell, J. P., ... Demou, E. (2020). Occupation and risk of severe COVID-19: Prospective cohort study of 120075 UK Biobank participants. Occupational and Environmental Medicine. https://doi.org/10.1136/oemed-2020-106731

Netemeyer, R. G., Boles, J. S., \& McMurrian, R. (1996). Development and validation of work-family conflict and family-work conflict scales. Journal of Applied Psychology, 81(4), 400-410. https://doi.org/10.1037/0021-9010.81.4.400

O’Reilly, A. (2020). "Trying to Function in the Unfunctionable": Mothers and COVID-19. In Journal of the Motherhood Initiative for Research and Community Involvement (Vol. 11, Issue 1). https://jarm.journals.yorku.ca/index.php/jarm/article/view/40588 Remery, C., André, S., Besamusca, J., Yerkes, M., Hummel, B., \& van der Zwan, R. (2021, November 24). De coronapandemie en de verdeling van huishoudelijke en zorgtaken in Nederland. Economisch Statistische Berichten. https://esb.nu/esb/20068400/decoronapandemie-en-de-verdeling-van-huishoudelijke-en-zorgtaken-in-nederland

Rogelberg, S. G., \& Stanton, J. M. (2007). Introduction: Understanding and dealing with organizational survey nonresponse. Organizational Research Methods, 10(2), 195-209. https://doi.org/10.1177/1094428106294693

Rudman, L. A., Moss-Racusin, C. A., Phelan, J. E., \& Nauts, S. (2012). Status incongruity and backlash effects: Defending the gender hierarchy motivates prejudice against female 
leaders. Journal of Experimental Social Psychology, 48(1), 165-179.

https://doi.org/10.1016/J.JESP.2011.10.008

Shockley, K. M., Clark, M. A., Dodd, H., \& King, E. B. (2021). Work-family strategies during COVID-19: Examining gender dynamics among dual-earner couples with young children. Journal of Applied Psychology, 106(1), 15-28.

https://doi.org/10.1037/ap10000857

Somarriba, N., \& Pena, B. (2009). Synthetic indicators of quality of life in Europe. Social Indicators Research, 94(1), 115-133. https://doi.org/10.1007/S11205-008-9356Y/TABLES/8

Sousa, C., Kuschel, K., Brito, A., \& Gonçalves, G. (2018). Work-oriented men and women: Similar levels of work-family conflict and guilt yet different coping strategies. Psychological Thought, 11(2), 195-211. https://doi.org/10.5964/psyct.v11i2.291

Tangney, J. P., Stuewig, J., \& Mashek, D. J. (2007). Moral emotions and moral behavior. Annual Review of Psychology, 58, 345-372. https://doi.org/10.1146/annurev.psych.56.091103.070145

Williams, J. C. (2020, May 11). The Pandemic Has Exposed the Fallacy of the "Ideal Worker.” Harvard Business Review. https://hbr.org/2020/05/the-pandemic-has-exposedthe-fallacy-of-the-ideal-worker

Yerkes, M. A., André, S. C. H., Besamusca, J. W., Kruyen, P. M., Remery, C. L. H. S., van der Zwan, R., Beckers, D. G. J., \& Geurts, S. A. E. (2020). 'Intelligent' lockdown, intelligent effects? Results from a survey on gender (in)equality in paid work, the division of childcare and household work, and quality of life among parents in the Netherlands during the Covid-19 lockdown. PLoS ONE, 15 (11 November), e0242249. https://doi.org/10.1371/journal.pone.0242249 


\section{Table 1}

Type of Essential Occupation

\begin{tabular}{|c|c|c|}
\hline Type of occupation & $\mathrm{N}$ & $\%$ \\
\hline Non-essential occupation & 286 & $49.9 \%$ \\
\hline Care, Youth Assistance and & 55 & $19.3 \%$ \\
\hline \multicolumn{3}{|l|}{ (social) support } \\
\hline Teachers and staff needed at & 111 & $19.3 \%$ \\
\hline \multicolumn{3}{|l|}{ school } \\
\hline Public transport & 1 & $0.2 \%$ \\
\hline Food chain & 10 & $1.7 \%$ \\
\hline Transport of fuels & 1 & $0.2 \%$ \\
\hline Transportation of waste and & 1 & $0.2 \%$ \\
\hline \multicolumn{3}{|l|}{ garbage } \\
\hline Childcare & 1 & $0.2 \%$ \\
\hline Media and communication & 9 & $1.6 \%$ \\
\hline Continuity of emergency & 5 & $0.9 \%$ \\
\hline \multicolumn{3}{|l|}{ services } \\
\hline Necessary government & 9 & $1.6 \%$ \\
\hline \multicolumn{3}{|l|}{ processes } \\
\hline My essential occupation is & 19 & $3.3 \%$ \\
\hline \multicolumn{3}{|l|}{ not listed } \\
\hline I do not know & 13 & $2.3 \%$ \\
\hline Total & 521 & $90.8 \%$ \\
\hline Missingness & 53 & $9.2 \%$ \\
\hline
\end{tabular}


WORK-FAMILY GUILT DURING COVID-19

Table 2

Descriptive Statistics and Intercorrelations Among Variables

\begin{tabular}{|c|c|c|c|c|c|c|c|c|c|}
\hline & $M$ & $S D$ & 1 & 2 & 3 & 4 & 5 & 6 & 7 \\
\hline $\begin{array}{l}\text { 1. Number of } \\
\text { children }\end{array}$ & 2.04 & 0.84 & - & & & & & & \\
\hline $\begin{array}{l}\text { 2. Age } \\
\text { (youngest) child }\end{array}$ & 8.25 & 7.14 & $-.15^{* *}$ & - & & & & & \\
\hline 3. Workhours ${ }^{\text {a }}$ & 35.28 & 9.34 & .01 & .04 & - & & & & \\
\hline 4. Time ${ }^{b}$ & 1.49 & 0.50 & .06 & $.32 * *$ & -.01 & - & & & \\
\hline 5. Gender ${ }^{c}$ & 1.64 & 0.48 & .02 & .03 & $-.42 * *$ & -.07 & - & & \\
\hline $\begin{array}{l}\text { 6. Essential } \\
\text { occupation }^{\mathrm{d}}\end{array}$ & 1.42 & 0.49 & .03 & .09 & $-.16^{* *}$ & .05 & $.18^{* *}$ & - & \\
\hline $\begin{array}{l}\text { 7. Work-family } \\
\text { guilt }\end{array}$ & 3.17 & 1.92 & $.12 * *$ & $-.21 * *$ & .02 & $-.21 * *$ & $.18 * *$ & $.11 *$ & - \\
\hline
\end{tabular}

Note. $N=506$ (after listwise deletion).

${ }^{a}$ Workhours per week.

${ }^{\mathrm{b}}$ Time (1 = W1 [March 2020], 2 = W2 [December 2020]).

${ }^{\mathrm{c}}$ Gender $(1=\operatorname{man}, 2$ = woman $)$.

${ }^{\mathrm{d}}$ Essential occupation ( 1 = non-essential occupation, 2 = essential occupation).

$* p<.05, * * p<.01$. 


\section{Table 3}

Summary of Hierarchical Regression Analysis for Variables predicting Work-Family Guilt

Predictor

$\beta \quad t \quad p$

$s r^{2}$

Step 1

\begin{tabular}{|c|c|c|c|c|}
\hline Number of children & .10 & 2.31 & $.021 *$ & .01 \\
\hline Age of youngest child & -.15 & -3.33 & $<.001 * * *$ & .02 \\
\hline Work hours ${ }^{a}$ & .04 & 0.96 & .339 & .002 \\
\hline Time $^{b}$ & -.18 & -3.93 & $<.001 * * *$ & .03 \\
\hline Essential occupation $^{c}$ & .14 & 3.22 & $.001 * * *$ & .02 \\
\hline \multicolumn{5}{|l|}{ tep 2} \\
\hline Gender $^{\mathrm{d}}$ & .20 & 4.25 & $<.001 * * *$ & .03 \\
\hline \multicolumn{5}{|l|}{ tep 3} \\
\hline Gender x Number of children & .21 & 1.34 & .180 & .003 \\
\hline Gender x Age of youngest child & -.18 & -1.08 & .268 & .002 \\
\hline Gender x Workhours & -.04 & -0.21 & .835 & .00008 \\
\hline Gender x Time & -.06 & -.28 & .784 & .0001 \\
\hline Gender x Essential occupation & .24 & 1.13 & .261 & .002 \\
\hline
\end{tabular}

Note. $N=506$ (after listwise deletion).

${ }^{a}$ Workhours per week.

${ }^{\mathrm{b}}$ Time (1 = W1 [March 2020], 2 = W2 [December 2020]).

${ }^{\mathrm{c}}$ Essential occupation ( 1 = non-essential occupation, 2 = essential occupation).

${ }^{\mathrm{d}} \operatorname{Gender}(1=$ man, 2 = woman $)$.

$* p<.05, * * p<.01, * * * p<.001$. 


\section{Table 4}

Descriptive Statistics and Intercorrelations Among Variables

\begin{tabular}{|c|c|c|c|c|c|c|c|c|c|}
\hline & $M$ & $S D$ & 1 & 2 & 3 & 4 & 5 & 6 & 7 \\
\hline $\begin{array}{l}\text { 1. Number of } \\
\text { children }\end{array}$ & 2.09 & 0.90 & - & & & & & & \\
\hline $\begin{array}{l}\text { 2. Age (youngest) } \\
\text { child }\end{array}$ & 9.93 & 7.58 & $-.27 * *$ & - & & & & & \\
\hline 3. Workhours ${ }^{\text {a }}$ & 34.85 & 9.93 & -.01 & .02 & - & & & & \\
\hline $\begin{array}{l}\text { 4. Essential } \\
\text { occupation }^{b}\end{array}$ & 1.46 & 0.50 & .01 & .05 & $-.23 * * *$ & - & & & \\
\hline 5. Gender ${ }^{\mathrm{c}}$ & 1.64 & 0.48 & .02 & .06 & $-.47 * * *$ & $.21 * * *$ & - & & \\
\hline $\begin{array}{l}\text { 6. Work-family } \\
\text { guilt }\end{array}$ & 2.76 & 1.82 & $.14^{* *}$ & $-.17 * *$ & .05 & $.15^{* *}$ & $.12 *$ & - & \\
\hline 7. Family & 3.53 & 1.67 & $.11 *$ & $-.27 * * *$ & .08 & .09 & .03 & $.60 * * *$ & - \\
\hline Prioritization & & & & & & & & & \\
\hline
\end{tabular}

Note. $N=298$ (after listwise deletion).

${ }^{a}$ Workhours per week.

${ }^{\mathrm{b}}$ Essential occupation $(1$ = non-essential occupation, 2 = essential occupation $)$.

${ }^{\mathrm{c}}$ Gender (1 = man, 2 = woman $)$.

$* p<.05, * * p<.01, * * * p<.001$. 


\section{Table 5}

Summary of Hierarchical Regression Analysis for Variables predicting Family Prioritization

\begin{tabular}{lllll}
\hline Predictor & $\beta$ & $t$ & $p$ & $s r^{2}$ \\
\hline Step 1 & .04 & .71 & .479 & .002 \\
Number of children & -.26 & -4.54 & $<.001^{* * *}$ & .06 \\
Age (youngest) child & .12 & 2.08 & $.038^{*}$ & .01 \\
Workhours ${ }^{\text {a }}$ & .13 & 2.22 & $.027^{*}$ & .02 \\
Essential occupation ${ }^{\text {b }}$ & & & & .007 \\
Step 2 & .09 & 1.47 & .143 & .29 \\
Gender ${ }^{\text {c }}$ & & & & \\
Step 3 & .56 & 11.69 & $<.001 * * *$ & .0002 \\
Work-family Guilt & & & & \\
Step 4 & -.05 & -.28 & .782 & \\
Work-family Guilt x Gender & & & & \\
\hline
\end{tabular}

Note. $N=298$ (after listwise deletion).

${ }^{a}$ Workhours per week.

${ }^{\mathrm{b}}$ Essential occupation ( 1 = non-essential occupation, 2 = essential occupation).

${ }^{\mathrm{c}} \operatorname{Gender}(1=$ man, 2 = woman $)$.

$* p<.05, * * p<.01, * * * p<.001$. 


\section{Figure 1}

Model of Work-family Guilt Mediating the Effect of Gender on Family Prioritization

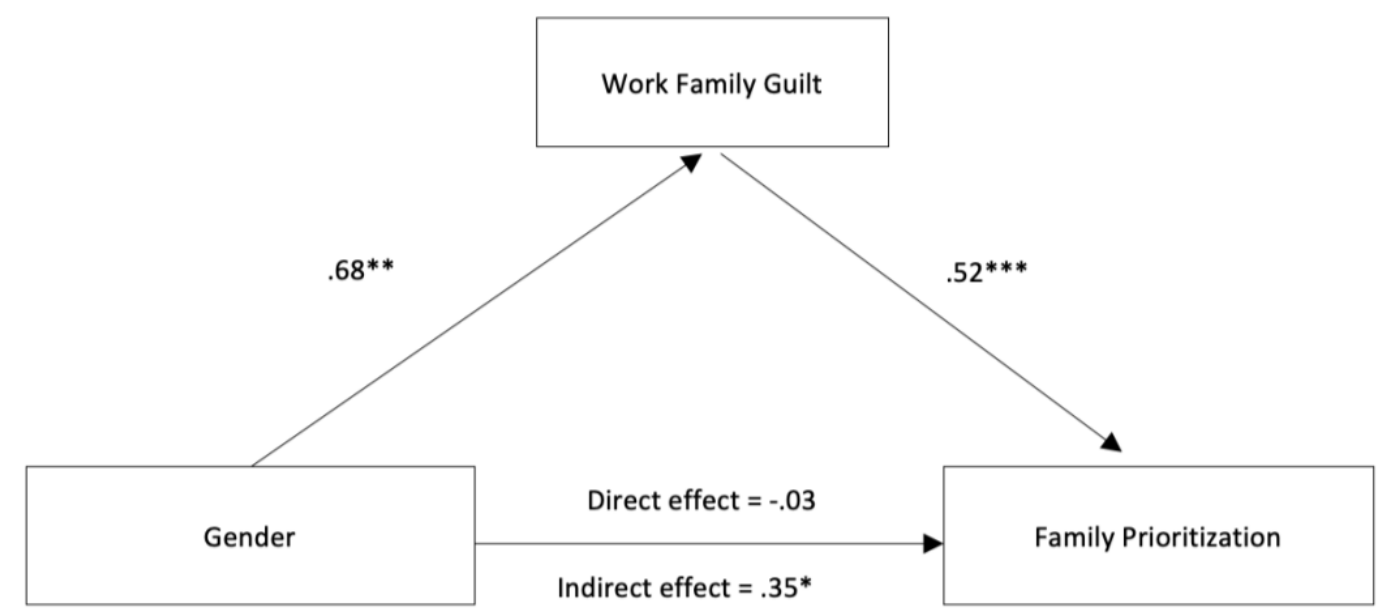

$* \mathrm{p}<.05, * * \mathrm{p}<.01, * * * \mathrm{p}<.001$.

Note: Gender ( 1 = man, 2 = woman $)$. 


\section{Figure 2}

Model of Work-family Guilt Mediating the Effect of Essential Occupations on Family

\section{Prioritization}

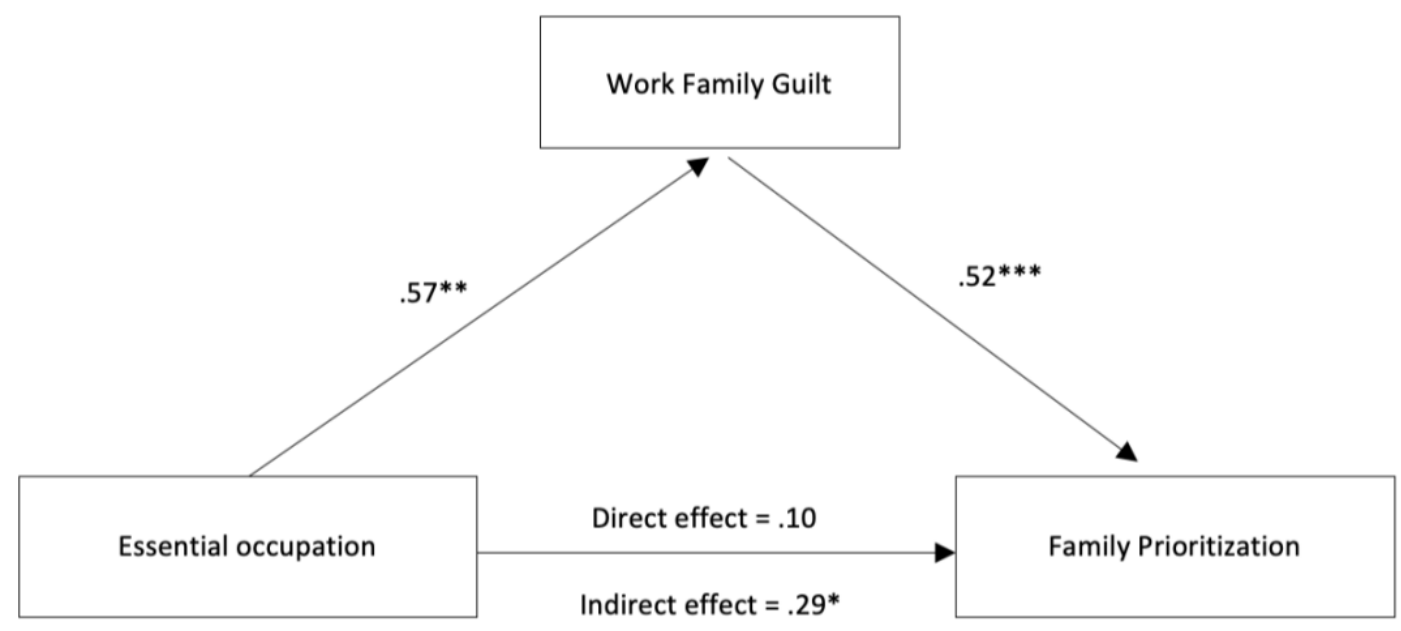

$* \mathrm{p}<.05, * * \mathrm{p}<.01, * * * \mathrm{p}<.001$.

Note: Essential occupation ( 1 = non-essential occupation, 2 = essential occupation). 


\section{Appendix A}

\section{Overview of COVID-19 Measures during Data Collection}

Wave 1 of the data was collected between May 27 - June 5, 2020 but most questions referred to the March 2020 lockdown in the Netherlands. The situation during the March 2020 lockdown measures included closures of childcare, primary schools and afterschool care facilities from 15 March until May 11. Secondary education was closed until partially reopening in June 2. During the mandated closures, schools and childcare remained open to parents working in essential occupations (available as a last resort in case other arrangements were not possible). Everyone was encouraged to work from home, with the exception of essential workers. People were encouraged to only use public transportation when necessary, in order to keep essential workers safe, as they relied on these services to get to work.

Wave 2 was collected between December 4 and December 20, 2020 and referred to the previous four weeks. During this time the Netherlands was in a partial lockdown until December 14 (e.g., closed hospitality sector) and measures were eased compared to the March 2020 lockdown (e.g., open schools and daycare). Four days before the end of data collection on December 15, the Netherlands entered a hard lockdown (with stricter measures than the March lockdown). 


\section{Appendix B}

\section{Measure Work-Family Guilt (Wave 1 and 2)}

\section{Question Instructions Wave 1}

"Please indicate the extent to which the statements below applied to you in recent times, since the corona crisis began."

\section{Question Instructions Wave 2}

"Please indicate the extent to which the statements below applied to you in the past four weeks."

\section{Work-Family Guilt Item (Wave 1 and 2)}

"I feel guilty that because of my work I am not able to take care of my family as well as I would like in this situation." Rated on a likert scale from 1 ("Totally disagree") to 7 (“Totally agree").

\section{Measure Family Prioritization (Wave 2)}

\section{Question Instructions}

"Please indicate the extent to which the following statements applied to you in the past four weeks."

Items

(1) "In the past few weeks, I have been thinking about how I can reduce my work hours so that I can spend more time with my partner/child(ren)." (2) "In the past few weeks, I have spent time that I actually wanted to spend on myself (e.g., for a hobby or to read a nice book), yet on my partner/child(ren)." Rated on a likert scale from 1 ("Totally disagree") to 7 ("Totally agree"). 


\section{Measure Essential Occupation (Wave 1 and 2)}

\section{Question Instructions Wave 1}

"Below is a list of occupations classified as "crucial occupations" by the Dutch government. Do you currently have a crucial occupation according to this list? Click the answer that best fits your work situation."

\section{Question Instructions Wave 2}

"Below is a list of occupations classified as "crucial occupations" by the Dutch government in March 2020. Do you currently have a crucial occupation according to this list? Click the answer that best fits your work situation."

\section{Categorical Options}

(1) No, I do not fall into the category of crucial occupations (2) Care, Youth Assistance and (Social) Support, including production and transportation of medicines and medical devices. (3) Teachers and staff needed at school, such as for distance learning, childcare and exams. (4) Public transportation. (5) Food chain: the food chain should be viewed broadly. It consists of supermarkets, the delivery of supermarkets, the processing industry and the transports of this industry but also the collection of products from farmers, the delivery of e.g. fodder and other products to farmers, the access of workers for the harvest. (6) Transport of fuels such as coal, oil, gasoline and diesel, etcetera. (7) Transportation of waste and garbage. (8) Childcare. (9) Media and communication: for the provision of information to the society that is necessary to keep abreast of what is happening. (10) Continuity of emergency services: control room processes, fire departments, ambulance services, GHOR, crisis management of the safety regions. (11) Necessary government processes (central government, provinces, municipalities and water boards), for example payment of benefits and allowances, civil affairs, consulates and embassies, judicial 
institutions and forensic clinics. (12) My crucial professional group is not listed, namely. (13) I don't know. 


\section{Appendix C}

\section{Explanation for Choice of Measure Items}

\section{Measure Family Prioritization}

We chose to measure the consideration of reducing workhours instead of whether participants reduced their workhours for two reason. Firstly, many workers do not have the ability to reduce their workhours or do not have the ability to reduce their workhours without formal process with certain repercussion (e.g., re-assignment or demotion). However, it was still important to capture the intent to reduce workhours in people who cannot reduce their workhours. Reducing one's leisure time, however, is not faced by the same constraints.

Secondly, while the outcome of workhour reduction is also relevant to examine, the current study aimed to measure compensation for work-family guilt (by prioritizing family) at the same time point at which work-family guilt is measured (i.e., whether work-family guilt experienced at time 1 is associated with greater compensation at time 1). While reducing one's leisure time can be done immediately, the reduction of one's workhours may have a lag time, as it might have been requested in the past (at time 0 ) but only just been processed (at time 1). Guilt is a moral emotion that motivates people to reduce it through compensation or targeted action (Cryder et al., 2012). It is, therefore, important to measure guilt and compensation at the same time, since compensation leads to a reduction of guilt, which in turn reduces the need to compensate. 